\title{
Study of the Antibody Response against Mycobacterium tuberculosis Antigens in Warao Amerindian Children in Venezuela
}

\section{Z Araujo/ ${ }^{+}$, JH de Waard*, C Fernández de Larrea, D López, C Fandiño, A Maldonado, E Hernández, Y O caña, R O rtega, M Singh**, Tom HM Ottenhoff***, SM Arend***, J Convit*}

\begin{abstract}
Cátedra de Inmunología, Escuela de Medicina “José María Vargas", Facultad de Medicina *Laboratorio de Tuberculosis, Instituto de Biomedicina, Universidad Central de Venezuela, Apartado 4043, Caracas 1010A, Venezuela **GBF and Lionex GmbH, Braunschweig, Germany ***Department of Infectious Diseases and Immunohematology and Blood Transfusion, Leiden University Medical Center, Leiden, the Netherlands
\end{abstract}

This study was aimed at investigating alternate methods for serodiagnosis of tuberculosis (TB), which are needed because bacteriologic diagnosis of childhood TB is difficult. A selection of 80 serum and saliva samples were tested from Warao indigenous children under 15 years of age; 34 high TB suspects (28 positive and 6 negative for the tuberculin skin test, TST) and 46 healthy contact children (32 positive and 14 negative for the TST). Several enzyme-linked immunosorbent assay (ELISA) serological tests were developed to test for Mycobacterium tuberculosis-specific antibodies, including serum $\operatorname{IgA}$, $\operatorname{Ig} G$, IgE, and secretory $\operatorname{IgA}(s \operatorname{IgA})$ in saliva against 3 specific antigens $(P P D, H S P 60,38 \mathrm{kDa}$ ). Of these, 2 antigens, PPD and $38 \mathrm{kDa}$, showed significantly higher reactivity. The sensitivity and specificity of these tests for diagnosis remained limited, between $26.5 \%$ and $38.2 \%$, and $77.4 \%$ and $97 \%$, respectively. Of all the samples studied and combinations realized between all isotypes and antigens combined with 3 isotypes (anti-PPD IgG, IgE, and anti-38kDa sIgA) managed to detect the largest number of patients, showing an improved sensitivity level of $64.7 \%$, although specificity levels dropped to $81.8 \%$. These results were compared with the Omega diagnostics commercial kit results. The commercial kits showed significantly lower reactivity (sensitivity of 20\% and $13.33 \%$ to Myco G and Complex Plus, respectively) and a specificity of 100\%. This study shows that in indigenous populations of Venezuela, where invasive procedures cannot be used to select samples but evaluation with a chest X-ray for radiological studies is available, the combination of 3 specific isotypes may be a useful tool to increase diagnostic accuracy with pulmonary $T B$ in this population, when used together with clinical and epidemiological criteria.

Key words: tuberculosis (TB) - Warao Amerindians - tuberculin skin test (TST) - IgA - IgG - IgE - secretory IgA (sIgA)

It has been reported that tuberculosis (TB) is a public health problem among indigenous communities of Venezuela, of whom $95 \%$ live in rural areas (OCEI 1992). Venezuelan Health Services reported among non-indigenous populations a rate between 26.1 and 24.8 and among indigenous populations a rate between 155.6 and 129.4 per 100,000 inhabitants between 1997 and 2001 (MSDS 2002). Since 1999, Delta Amacuro State has presented the highest rates, between 93.2 and 81 per 100,000 inhabitants. Of these, $90 \%$ of the cases were present in the indigenous Warao population, with a very high prevalence of adult TB (MSAS 1999, MSDS 2002). When we carried out a TB diagnostic study on the Warao child population, we found the extremely high TB rate of 3190/100,000 in children under 15 years of age (Fernández de Larrea et al. 2002).

Financial support: the World Bank and Ministerio de Sanidad y Asistencia Social de Venezuela (Project BM/MSAS/PCEE-VEN/ 96/002-021-034), Consejo Nacional de Ciencia y Tecnología (Project S1-2000000667)

${ }^{+}$Corresponding author. Fax: +58-212-564.2978. E-mail: zaraujo@telcel.net.ve

Received 28 October 2003

Accepted 21 July 2004
Studies that address the difficulties of TB diagnosis in children and attempts to improve diagnostic methods are not new (Eamranond \& Jaramillo 2001). Although there are various scoring systems for the diagnosis of TB in children, these are often underutilized, misused or not used at all, and the sensitivity and specificity are variable. Since the bacilli-containing sputum is usually swallowed, especially when the children cannot produce a sufficient sputum sample, several diagnostic methods - including the polymerase chain reaction (PCR), high resolution computerized tomography (CT) and improved serological tests - are recommended (Eamranond \& Jaramillo 2001, Honore et al. 2001).

In recent years, antigen or antibody detection tests such as enzyme immunoassays have largely replaced culture for the diagnosis of many infectious diseases because they can be performed in intermediate-level laboratories with relatively simple equipment (Mabey et al. 2004). In relation to the serological tests for immunodiagnosis of TB, several combinations using different antigens or specific antibodies to increase sensitivity and specificity of serological testing of TB in adult patients have been reported (Daniel \& Debane 1987, Chiang et al. 1997, Pottumarthy et al. 2000).

Very few studies have addressed the problem in the diagnosis of childhood TB. The use of ELISA for 
immunodiagnosis of TB has shown that the humoral response to mycobacterial antigens is low in children, especially when combined responses against antigens or specific antibodies are not used (Starke 1993, Swaminathan et al. 1999, Sant'Anna et al. 1999). Non-recombinant and recombinant antigens of Mycobacterium tuberculosis such as purified protein derivative (PPD) and $38 \mathrm{kDa}$ and HSP60, respectively have been used for the serodiagnosis of TB. There are many reports on the sensitivity and specificity of these antigens for serodiagnosis of TB, with the results being variable (Radin et al. 1983, Young et al. 1986, Alde et al. 1989, Zheng et al. 1994, Chiang et al. 1997, Raja et al. 2002).

Since in rural areas of Venezuela such as those of the indigenous Warao communities, where there is no access to a large hospital, and considering that invasive procedures cannot be used to take samples in these communities, in the absence of an ideal standard test, a positive result from a more sensitive, less specific test is considered a reliable indicator of children highly suspected of TB. It is essential to improve the diagnosis of TB in this childhood population. In this paper we report on the evaluation of several ELISA serological tests that were used to detect M. tuberculosis-specific antibodies, serum IgA, IgG, and IgE against PPD and HSP60 and secretory IgA in saliva against $38 \mathrm{kDa}$ antigens.

\section{MATERIALS AND METHODS}

Since 1996 the Regional Delta Amacuro Tuberculosis Program and the Tuberculosis Laboratory of the Institute of Biomedicine have been actively diagnosing TB cases among the Warao communities based on respiratory symptoms characteristic of TB, the tuberculin skin test (TST), and smears and/or cultures; they have been prescribing specific treatments. A descriptive transversal study was carried out between 2000 and 2001 in which a total population of 502 children under the age of 15 years old residing in the visited communities was examined. A total of 80 children were selected for the study. A single serum sample and saliva sample were collected from all children studied (of either sex and with average age of $8.24 \pm 4.84$ years old). Bearing in mind that the WHO uses the criteria of presence of weight loss or inadequate weight gain, coughing or wheezing and a history of household contact with an adult case of lung TB, and that these criteria have had a positive predictable value between $63 \%$ and $70 \%$ (Migliori et al. 1992, Houwert et al. 1998), we adopted a previously-reported scheme (Fernández de Larrea et al. 2002), which takes into account the clinical, nutritional, and epidemiological factors in the children, specifically (1) clinical and nutritional criteria and positive reactivity to tuberculin, and (2) clinical and nutritional criteria, with negative tuberculin and positive household contact. During our study specific attention was given to Warao children with respiratory symptoms which suggested TB and were therefore further evaluated with a chest X-ray. Radiological studies suggested that 34 children were highly suspected TB cases. The children were grouped as follows: Warao patient group - children with probable active TB [clinically, radiologically and/or bacteriologically diagnosed (Fernández de Larrea et al. 2002)] before treat- ment ( $\mathrm{n}=34,15$ females and 19 males), 28 positive and 6 negative for the TST; Warao control group - healthy contact controls ( $n=46,31$ females and 15 males), 32 positive and 14 negative for the TST. All control children were evaluated with the rating system mentioned above and none was found with characteristic signs of TB. Registration of the presence or non presence of BCG scars was carried out.

Inclusion criteria for both study groups - (1) Patients and controls included a Warao population of children between 1 month and 15 years old without or with respiratory symptoms, the latter suggesting pulmonary tuberculosis; (2) Only the O blood group Rh+ children of both patient and control groups were included in this study because the Venezuelan indigenous populations are fundamentally O blood group (Arends 1992); (3) Since in Venezuela's National Tuberculosis Program the BCG vaccine is given in the first month of age, patients and controls included children with presence or non presence of BCG scars; (4) Patient group: children with probable active TB, based on clinical diagnosis, thorax radiography, smears stained with Ziehl-Neelsen and/or microbiological culture without or with positive TST $(\geq 10 \mathrm{~mm}) ;(5)$ Control group: healthy subjects with no evidence of clinical, microbiological or radiographic signs of pulmonary TB without or with positive TST; (6) Only patients with probable active TB who were HIV negative were included in this study, (the results revealed no case of HIV-positive TB among the Warao children). Consent was obtained from all participants or their legal representatives (children or parents, respectively), who signed a "consent form" agreement before blood and saliva samples were selected. The approval of the Ethical Commission of the Biomedicine Institute was also obtained.

\section{Confirmatory studies}

Radiological - Despite difficult access, thorax radiology studies were performed on all highly suspected cases according to standard techniques in post-anterior projection. This took place in the radiology service of the Hospital Luis Razzetti, Tucupita.

Bacteriological - Given that invasive procedures cannot be used to select samples in these communities, a study of secretions of the pharynx and attempts to obtain samples of sputum by expectoration in children older than 10 years old was carried out in all highly suspected cases. Smears from sputum were stained by the Ziehl-Neelsen direct method. For each specimen (sputum or secretions of the pharynx) 2 tubes of modified Ogawa egg medium and Lowënstein-Jensen were inoculated using the swab method of Kudoh and Kudoh (for sputum as well as oozing) (Kudoh \& Kudoh 1974). Specific treatments were initiated in all newly identified cases of TB following the norms of the Venezuelan National Tuberculosis Control Program (MSAS 1996).

Therapeutic conduct - Anti-TB treatment was initiated on all highly suspected cases, where radiological evidence suggestive of TB or bacteriological confirmation by bacilloscopy or culture was found. During and after anti-TB drugs treatment, clinical and nutritional monitoring on all highly suspected patients was carried out in 
order to evaluate the improvement of these aspects as therapeutic confirmation, which allowed us to corroborate the diagnosis.

Immunological studies

The TST - The TSTs were performed on all the individuals of this study using 2 tuberculin units of PPD of M. tuberculosis, strain RT-23, supplied by the Copenhagen World Health Organization reference laboratory (Denmark) and in current use by the Venezuelan Health Services. Testing and reading were done according to international guidelines (Snider 1982, Arnadottir et al. 1996). In order to evaluate the possibility of non-specific anergy, skin test reactivity to Candida albicans was also carried out. The Candida antigen was provided by the Laboratory of Micology, Institute of Biomedicine. Both intradermal injections of $0.1 \mathrm{ml}$ solutions were administered by a trained nurse (the Regional Delta Amacuro Tuberculosis Program) into the volar surface of the left (tuberculin PPD) and right ( $C$. albicans antigen) forearm. The diameters of indurations were measured $72 \mathrm{~h}$ after inoculations; indurations of $\geq 10 \mathrm{~mm}$ and $\geq 5 \mathrm{~mm}$ were used as the criterion for infection with $M$. tuberculosis and C. albicans, respectively.

Antibodies to M. tuberculosis antigens - Immunoenzymatic assays were performed blindly by a lab technician, and developed and standardized in our laboratory for the measurement of antibodies (IgA, IgG, $\operatorname{IgE}$, sIgA) against PPD, HSP60, and $38 \mathrm{kDa}$ antigens. Each assay included positive and negative sera and blanks to control non-specific binding.

Serum IgA anti-PPD - The levels of anti-PPD IgA were determined in serum by an ELISA as follows. Sera were isolated from venous blood obtained from controls and TB patients. Microtiter plates (Immunolon) with 96 wells were coated with PPD (Statens Seruminstitut, Copenhagen $),(1 \mu \mathrm{g} / \mathrm{well}$ of each antigen in carbonate-bicarbonate buffer $\mathrm{pH} 9.6$ ) overnight at $4^{\circ} \mathrm{C}$. Excess protein binding sites were blocked by incubation with $1 \% \mathrm{BSA}$ in PBS at $37^{\circ} \mathrm{C}$ for $2 \mathrm{~h}$. Then the plates were washed 4 times with PBS containing $0.1 \%$ Tween 20. Samples diluted 1:50 in PBS containing $0.5 \%$ BSA were added and plates were incubated for $2 \mathrm{~h}$ at $37^{\circ} \mathrm{C}$. The plates were washed 4 times, then incubated with the second antibody (peroxidaseconjugated monoclonal antibody anti-alpha chain IgA (Sigma-Aldrich, US) diluted 1:1000 in blocking solution) for $1 \mathrm{~h}$ at $37^{\circ} \mathrm{C}$ and washed 4 times. After washing, substrate solution ( $30 \mu \mathrm{l}$ of $30 \% \mathrm{H}_{2} \mathrm{O}_{2}$ and $10 \mathrm{mg}$ o-phenylenediamine (OPD) dihydrochloride, Sigma-Aldrich) in $25 \mathrm{ml}$ citrate buffer, $\mathrm{pH} 5$ was added and incubated for 6 min at room temperature. Colour development was measured in an ELISA reader at $492 \mathrm{~nm}$.

Serum IgG anti-PPD and HSP6O - The levels of antiPPD and HSP60 IgG were determined in serum by an ELISA similar to that described for anti-PPD serum IgA. The serum samples were diluted 1:400 in blocking solution, and peroxidase-labeled anti-gamma chain IgG monoclonal antibody (Anti-human IgG HRP-conjugate, Promega Corporation, US) was used as the second antibody.

Serum IgE anti-PPD - The levels of anti-PPD IgE were determined by a similar ELISA to that described for antiPPD IgA. The serum samples were diluted 1:50 in block- ing solution, and biotin-labeled anti-epsilon chain IgE monoclonal antibody (Anti-human IgE, Epsilon Chain Specific, Vector Laboratories) was used as the second antibody.

sIgA anti $38 \mathrm{kDa}$ - The levels of sIgA in saliva were determined by a similar ELISA to that described for serum IgA anti-PPD. Microtiter plates (Immunolon) were coated overnight at $4^{\circ} \mathrm{C}$ with $38 \mathrm{kDa}$ antigen $(1 \mu \mathrm{g} / \mathrm{well}$ of antigen in carbonate-bicarbonate buffer $\mathrm{pH}$ 9.6). The saliva samples were diluted 1:10, and peroxidase-conjugated monoclonal antibody anti-alpha chain IgA (Sigma-Aldrich) was used as the second antibody. A group of 38 healthy non Warao children negative for the TST from a non endemic area of Caracas was included for the evaluation of positive sera based on the cut-off values.

Commercial kits - The results were compared with the Omega diagnostics commercial kit results (PathozymeMyco ${ }^{\circledR}$, Omega Diagnostics, and Pathozyme-TB Complex Plus ${ }^{\circledR}$, Omega Diagnostics).

Statistical analysis - The evaluation of positive sera was based on a positive score represented by optical density values (OD) above the cut-off point of the mean value plus 2 standard deviations of sera from a healthy control group from Caracas, the capital of Venezuela. The results are shown in OD x 1000. The statistical analysis used to compare the significance of the differences between the percentage values of $\operatorname{sg} \mathrm{A}$ and serum $\operatorname{Ig} \mathrm{A}, \mathrm{IgG}$, and IgE levels was Fisher's exact test and the Pearson test for correlations. The significance of the differences among the mean of the levels of isotypes between patient and control groups was estimated by Student's $t$ test.

\section{RESULTS}

Clinical and bacteriological studies - Radiological: thorax radiology was practiced on all highly suspected cases, which comprised 34/80 (42.5\%) of the children. Bacteriological: study of 22 secretions of the pharynx and 5 sputum samples obtained by expectoration in children older than 10 years old showed that in $3 / 34(8.8 \%)$ of patients there was bacteriological confirmation, while $1 \mathrm{spu}-$ tum (20\%) and 1 secretion of the pharynx (4.5\%) were positive by culture and 1 sputum by smear examination (20\%).

Immunological responses for the tuberculin PPD skin reaction - Distribution of indurated tuberculin PPD responses is shown in Fig. 1. Reactions of $\geq 10 \mathrm{~mm}$ were found in 28/34 (82.3\%) of the patients and in 32/46 (69.5\%) of the controls (data not shown). Tuberculin negative reactivity of controls and patients was found in 14/46 (30.4\%) and $6 / 34(17.6 \%)$, respectively. In the latter group, we found that $14.7 \%$ of children presented reactions of $0-4 \mathrm{~mm}$ and $2.9 \%$ of $5-9 \mathrm{~mm}$. When the skin test reactivity was carried out in order to evaluate the state of non-specific anergy in patients negative for the TST, we found that there was a high percentage of patients negative for tuberculin and Candida skin tests (80\%). A significant correlation between patients with tuberculin and Candida negative responses was found $(\mathrm{p}<0.001)$ (data not shown). Positive reactions of patients and controls showed a similar frequency of reactivity ( $26.4 \%$ and $23.9 \% 10-14 \mathrm{~mm}$, respectively and $55.8 \%$ and $45.6 \% \geq 15 \mathrm{~mm}$, respectively) (Fig. 


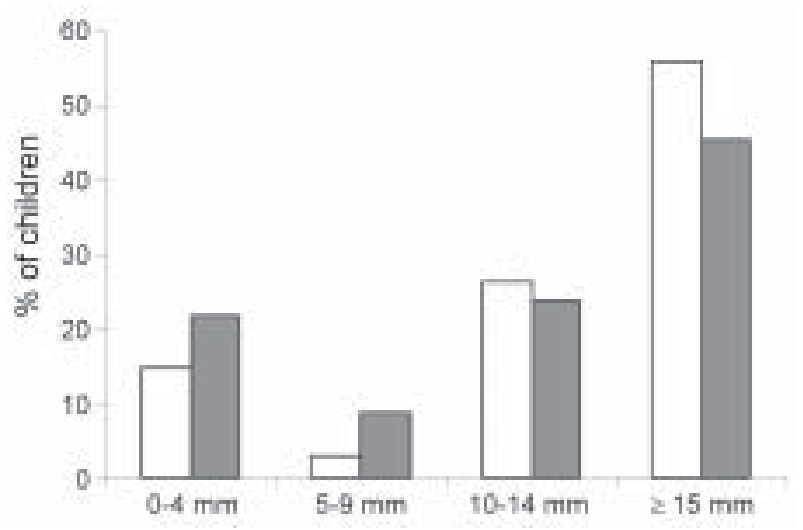

Fig. 1: distribution of the response to the tuberculin skin test (TST response) among the population of children studied. Patients $(\mathrm{n}=$ 34) (empty bars) and controls $(n=46)$ (filled bars)

1). The results concerning the cellular immune response to TST and the BCG vaccination status showed an increased percentage of reactions $\geq 10 \mathrm{~mm}$ in patient and control children older than 7 years old $[15 / 28(53.5 \%)$ and $22 / 32(68.7 \%)$, respectively] independent of the BCG status (data not shown).
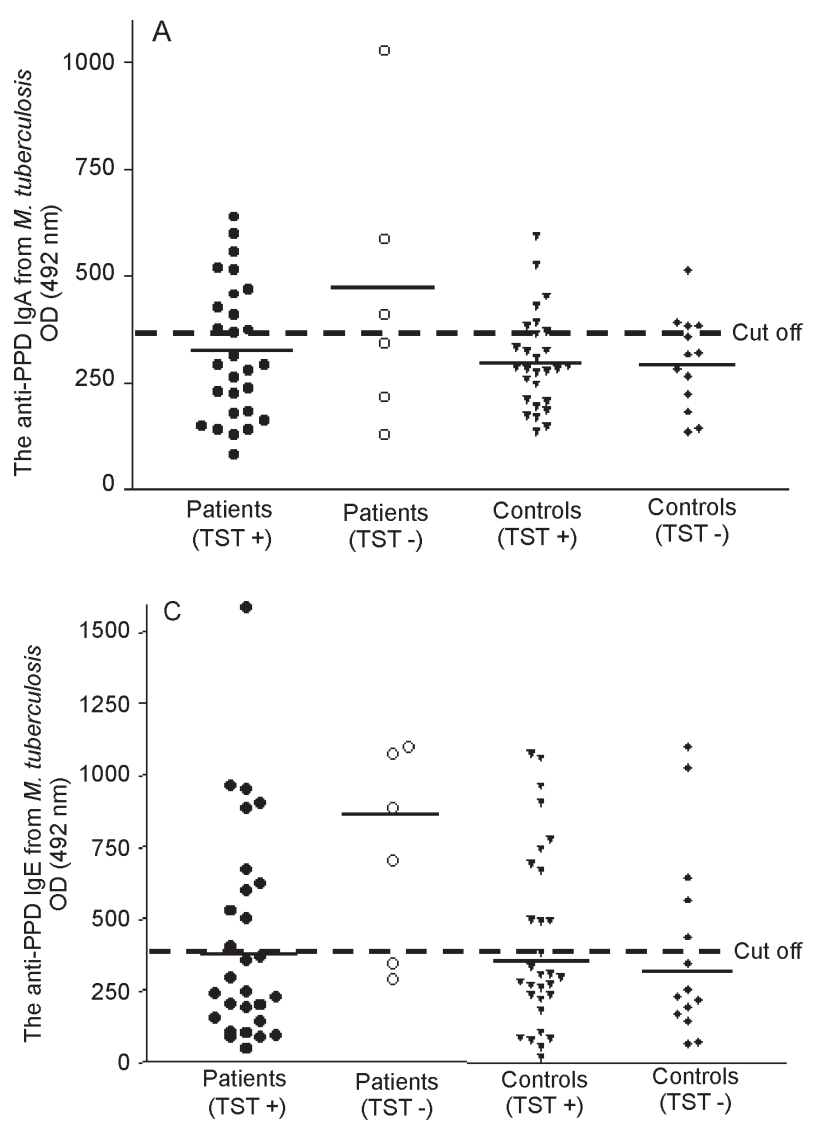

Antibodies to specific antigens according to the TST - The mean and distribution values of the OD related to the cut-off are shown in Fig. 2. The cut-off criteria for antiPPD IgA, IgG, and IgE and anti-38 kDa sIgA were 0.384 (Fig. 2A), 0.674 (Fig. 2B), 0.633 (Fig. 2C) and 0.730 (Fig. 2D), respectively, of patients and controls according to the TST. The percentages of patients and controls with positive or negative responses to specific antigens according to the TST are shown in Fig. 3. For anti-PPD IgA, concerning the $\operatorname{IgA}$ specific response according to the TST, sera from patients and controls positive or negative for the TST showed a similar percentage of subjects with IgA antibodies reactive to PPD antigen. Similarly, there was no statistically significant difference in the calculation of the percentage of children with anti-HSP60 IgG response between children positive and negative for the TST (data not shown). In contrast, concerning the antiPPD IgG response, sera from patients positive for the TST showed a significant percentage of children with specific $\operatorname{IgG}(32.1 \%, 9 / 28)$ in comparison to controls positive for the TST $(3.1 \%, 1 / 32) \mathrm{p}<0.004$ (Fig. 3).

Among children negative for the TST in the patient group, there was a significant percentage of subjects with anti-PPD $\operatorname{IgE}(66.6 \%, 4 / 6)$ in comparison to patients positive for the TST $(21.4 \%, 6 / 28), \mathrm{p}<0.04$ (Fig. 3). In the
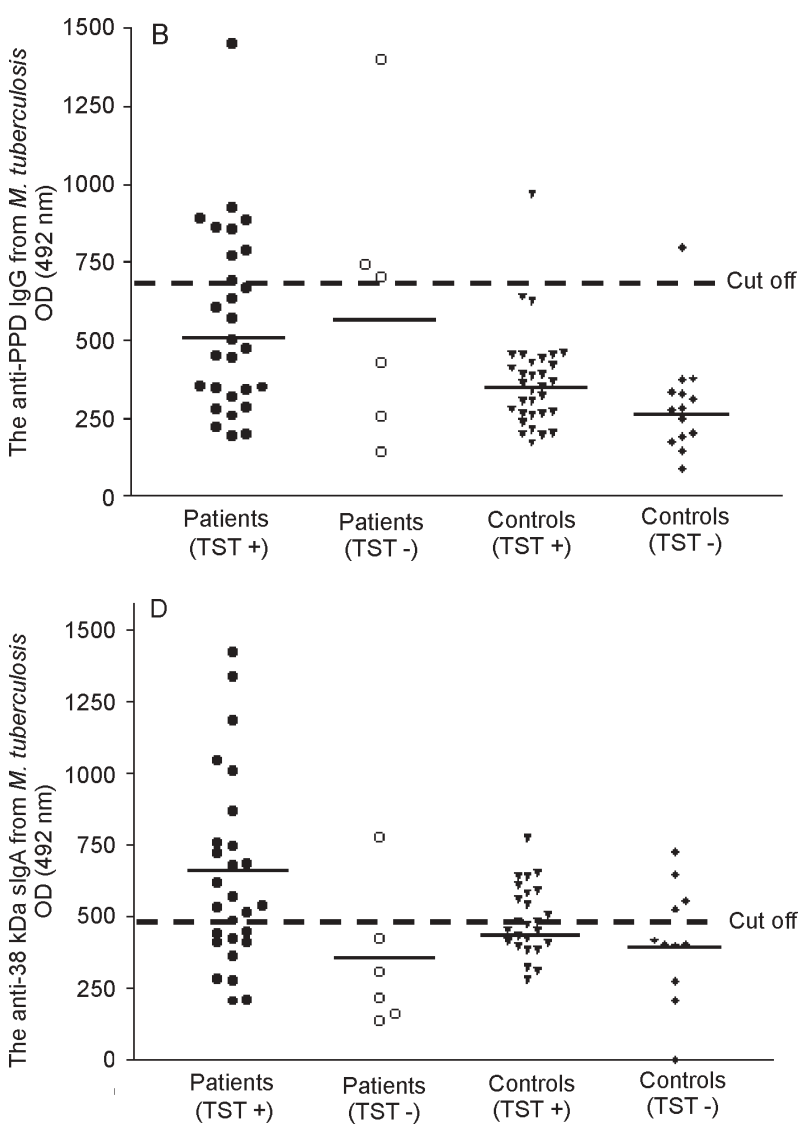

Fig. 2: distribution values of optical density (OD) and cut-off of the antibody tests. Patients and controls humoral reactivity against tuberculin PPD and $38 \mathrm{kDa}$ antigens, expressed as OD. The horizontal line and horizontal bar indicate the mean and cut-off, respectively. A group of 38 healthy non Warao children negative for the tuberculin skin test (TST) from a non endemic area of Caracas was included for the evaluation of positive sera based on the cut-off value. The cut off for anti-PPD IgA, IgG, IgE, and anti-38 kDa sIgA were 0.384 (A), $0.674(\mathrm{~B}), 0.633(\mathrm{C})$, and $0.730(\mathrm{D})$, respectively. 


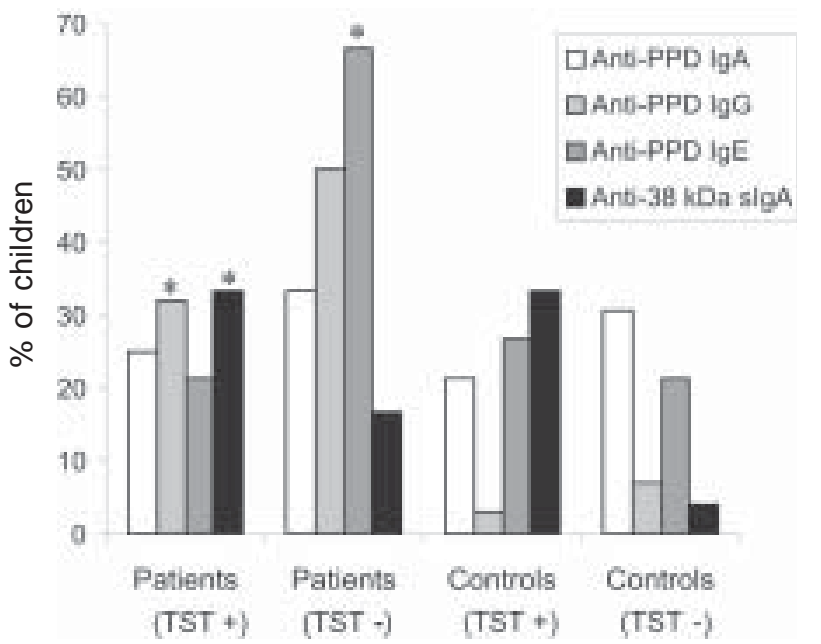

Fig. 3: data representing the percentage of patients and controls children with specific antibodies according to the response to the tuberculin skin test (TST) response. Anti-PPD IgA ( $\square$ ), anti-PPD $\operatorname{IgG}(\square)$, anti-PPD IgE ( $\square$ ), anti-38 kDa $\operatorname{sigA}(\square)$. The evaluation of positive sera was based on a positive score represented by optical density (OD) values above the cut-off point of the mean value plus 2 standard deviations of sera from a healthy control group $(n=38)$ from Caracas, the capital of Venezuela. For antiPPD IgG and anti-38 kDa sIgA significant differences were observed between patient (TST + ) and control (TST +). For anti-PPD IgE a significant difference was observed between patient (TST -) and patient $(\mathrm{TST}+)$.

control group, there was no statistically significant difference in the percentage of children with specific IgE response between children positive and negative for the TST - 26.6\%, 80/30 and 21.4\%, 3/14, respectively (Fig. 3). Patients positive for the TST comprised a significant percentage of children with $\operatorname{sIgA}$ antibodies reactive to 38 $\mathrm{kDa}(33.3 \%, 9 / 27)$ in comparison to controls negative for the TST (4\%, 1/25), p < 0.01 (Fig. 3).

Sensitivity and specificity of the tests - The sensitivity and specificity of the different tests are shown in the Table. The specific antibodies anti-38 kDa sIgA, antiHSP60 IgG, anti-PPD IgA, IgG, and IgE showed a sensitivity between $26.5 \%$ and $38.2 \%$ and a specificity between $77.4 \%$ and $97 \%$. The combination of specific serum antibodies IgG and IgE against PPD and sIgA in saliva to 38 $\mathrm{kDa}$ showed a sensitivity of $64.7 \%$ and a specificity of $81.8 \%$ (Table). These results were compared with the Omega diagnostics commercial kit results (Pathozyme Myco $\mathrm{G}^{\circledR}$ and Pathozyme Complex Plus ${ }^{\circledR}$ ). The commercial kits showed significantly lower reactivity (sensitivity of $20 \%$ and $13.33 \%$ to Myco G and Complex Plus, respectively) with $100 \%$ specificity.

\section{DISCUSSION}

Bearing in mind that the sensitivities of culture and smear drop precipitously when applied to children, and other diagnostic test/criteria take on greater importance such as serological tests, especially combined tests (Alifano et al. 1996, Gupta et al. 1997, Swaminathan et al. 1999, Pottumarthy et al. 2000, Imaz et al. 2001), the present
TABLE

Sensitivity and specificity of the different tests

\begin{tabular}{lcc}
\hline Specific antibodies & $\begin{array}{c}\text { Sensitivity } \\
(\%)\end{array}$ & $\begin{array}{c}\text { Specificity } \\
(\%)\end{array}$ \\
\hline Anti-PPD IgG & 38.2 & 95.8 \\
Anti-PPD IgE & 32.4 & 77.4 \\
Anti-PPD IgA & 26.5 & 92.8 \\
Anti-38 kDa sIgA & 36.1 & 91.6 \\
Anti-HSP60 IgG & 33.3 & 97.0 \\
MTB & 20.0 & 100.0 \\
M. sp. & 13.3 & 100.0 \\
Anti-PPD IgG, IgE and & 64.7 & 81.8 \\
Anti-38 kDa sIgA & & \\
\hline
\end{tabular}

PPD and $38 \mathrm{kDa}$ : Mycobacterium tuberculosis antigens; MTB: Panthozyme Myco ${ }^{\circledR}$, M. sp.: Panthozyme Complex Plus ${ }^{\circledR}$

study was performed to evaluate the diagnostic potential for detection of IgA, IgG, IgE, and sIgA against $M$. tuberculosis antigens. The results showed that in a significant percentage of children, the antibody levels to different $M$. tuberculosis antigens were raised in patients highly suspected of TB and were particularly high for anti-PPD IgE in patients with tuberculin negative reactivity.

The sensitivity of the anti-HSP60 IgG, and anti-PPD $\mathrm{IgG}, \operatorname{IgA}$, and $\mathrm{IgE}$ and anti-38 kDa sIgA tests for immunodiagnosis remained limited between $26.5 \%$ and $38.2 \%$, which makes it a poor diagnostic tool for disease confirmation. In order to improve the sensitivity tests, combinations realized between 3 isotypes and 2 antigens - antiPPD IgG, IgE, and anti-38kDa sIgA - used to detect the larger number of patients, allowed us to obtain a sensitivity level of $64.7 \%$, even though specificity levels dropped to $81.8 \%$. When we carried out a study of this combination method in a population of 19 non Warao children, all of them positive for the TST, from a place with low prevalence of latent and active infection (Coporito, Tucupita Municipal District of Delta Amacuro State), the combination showed that the differences of the specificities in these 2 populations were not significant $(78.1 \%$ and $81.8 \%$ in non Warao and Warao children, respectively, data not shown).

As mentioned above 3 antigens were evaluated, of which 2 antigens, PPD and $38 \mathrm{kDa}$, showed significantly higher reactivity. The PPD, a non-recombinant antigen, had shown variable sensitivity and specificity in previous reports (Radin et al. 1983, Starke 1993). We found for anti PPD-IgG, IgA, and IgE antibodies, a sensitivity between $26.5 \%$ and $38.2 \%$ and a specificity of $77.4 \%$ and $95.8 \%$. Our sensitivity results of $38.2 \%$ for anti-PPD IgG are similar to those found by others using PPD (Barrera et al. 1989, Starke 1993, Zheng et al. 1994, Raja et al. 2001). It has been reported that patients with active TB clearly had higher levels of IgG antibody to PPD antigen than did a healthy control group. However, no IgE antibodies were found (Radin et al. 1983). In our work, we found high IgE levels in both control and probable active TB cases. These different findings may be attributable to differences in the respective study population or methodology. Many re- 
ports have confirmed that specific IgE antibodies, a marker of Th2 responses, are elevated in TB and were correlated with disease incidence (Yong et al. 1989, Beyer et al. 1998, Adams et al. 1999). In addition, it has been reported that IgE concentrations decreased after successful treatment of TB, presumably due to the enhancement of a Th1 response, which suggests that TB up-regulates the Th2 response (Yong et al. 1989, Beyer et al. 1998). The high percentage of control children with specific IgE antibodies can be explained since the Warao population has a very high prevalence of adult $\mathrm{TB}$, which suggests that Warao children have frequent contact with chronic pulmonary TB (Fernández de Larrea et al. 2002). If true, the high levels of specific IgE could be a result of a recent TB infection, where apparently healthy contact children could have transiently higher antibody levels of this isotype, which could be beneficial from an early diagnosis point of view since children could be identified as individuals susceptible to M. tuberculosis. However, false-positive (environmental non-tuberculous micobacteria) does occur.

When the diagnostic for detection of anti-HSP60 IgG was evaluated, our findings showed that both anti-PPD and HSP60 IgG tests presented an overlap of reactivity in the patient group, as has been reported by other researchers (Barrera et al. 1989). These findings suggest that the measurement of the anti-HSP60 IgG antibodies should be excluded from the combination. In addition, it has been proposed by the WHO that the new diagnostic methods should have sensitivity at least higher than bacilloscopy (more than 50\%) and specificity higher than 95\%. Although our results using anti-PPD and anti-HSP60 IgG showed a higher rate of specificity ( $95.8 \%$ and $97 \%$, respectively), the sensitivity of these tests was lower than $50 \%$ (38.2\% and $33.3 \%$, respectively). On the other hand, taking into account that the children do not produce a sufficient sputum sample and that among the Warao child population recurrent or overwhelming parasite infections with protozoa and helmintic parasites and also malnutrition at early ages occur (González et al. 2003, Araujo et al. 2003), it seems to be important to improve the sensitivity of any new diagnostic method that puts more emphasis on the early detection of children with TB among high risk groups such as the indigenous Warao (Fernández de Larrea et al. 2002). Since sensitivity of the tests remained limited to between $26.5 \%$ and $38.2 \%$, and in order to improve the sensitivity of an antibody detection test, it seems important to combine the responses against different mycobacterial antigens. To assess the applicability of the combination of several antigens and specific antibodies for use in diagnosis of childhood TB, a combination including anti-38 $\mathrm{kDa}$ SIgA provided improvement in the diagnosis. There are many reports on the sensitivity and specificity of $38 \mathrm{kDa}$ antigen for serodiagnosis of TB which are about $80 \%$ (Young et al. 1986, Jackett et al. 1988). Measurement of $38 \mathrm{kDa}$ antibodies showed a sensitivity greater than $71.4 \%$ in adults TB, through a combination of assays for $\operatorname{Ig} G+\operatorname{Ig} A+\operatorname{IgM}$, while the specificity was $90 \%$ (Uma et al. 2001). In addition, it has been reported that sIgA in sputum was significantly higher in smear negative and culture positive cases compared with culture negative cases (Uma et al. 2001).
Few studies have addressed the detection of $\operatorname{sIg} \mathrm{A}$ against $M$. tuberculosis antigens in children. In this regard, when we applied the $38 \mathrm{kDa}$ antigen to estimate the specific sIgA in saliva, the measurement of $38 \mathrm{kDa}$ antibodies showed a sensitivity of $36.1 \%$, while the specificity was $91.6 \%$. In the patient group, $16.7 \%$ were positive for $38 \mathrm{kDa} \operatorname{sig} \mathrm{A}$ but did not have detectable antibodies to PPD (anti-PPD IgG and IgE). On the other hand, our results were compared with the Omega diagnostics commercial kit results (Pathozyme Myco ${ }^{\circledR}$ and Pathozyme Complex Plus ${ }^{\circledR}$ ). The commercial kits showed significantly lower reactivity (sensitivity of $20 \%$ and $13.33 \%$ to Myco $\mathrm{G}$ and Complex Plus, respectively) with $100 \%$ specificity.

Concerning the tuberculin response, it has been reported that overall $10 \%$ of patients with active TB fail to react to PPD (McMurray \& Echererri 1978, Wright et al. 1995). Our findings showed that a significant $17.6 \%$ of tuberculin negative reactivity was found in the patient group. When we used the Candida skin test to evaluate the non-specific anergic state in these children, the results showed that $80 \%$ of the tuberculous patients who are tuberculin negative did not respond to Candida antigen. These findings suggest that there are factors that must be associated with a significant frequency of anergic states in this population, a possibility conditioned by the high rate of parasite, viral and bacterial infections and malnutrition, which are frequently present in these communities. Concerning the antibody response according to the response to the TST, for anti-PPD IgA and IgG and anti-38 kDa $\operatorname{sg} \mathrm{A}$ antibodies, there was no statistically significant difference between tuberculin positive and negative children. However, for anti-PPD IgE there was a statistically significant difference between tuberculin positive and negative patients. The latter particularly, in contrast to their diminished lack of skin test reactivity, had high levels of antibodies. The vast majority of these antibodies were found to be of the $\mathrm{IgE}$ isotype, generally reported to be interleukin-4-dependent (Yong et al. 1989, Adams et al. 1999), which could condition the high frequency of anergic states observed in this group.

It may seem that the sample size was very small for the evaluation of the different diagnostic tests, but it should be borne in mind that testing is extremely difficult with indigenous communities because of problems of access and ethical considerations. Therefore it is inevitable that sampling is on a reduced scale. These limitations also explain why it was not possible to carry out evaluation of non Mycobacterium TB antigens. However, despite the limitations, it should be emphasized that the combination test achieved the highest sensitivity among all the tests, although admittedly the values are still low in terms of general standards. With further analysis it should be possible to improve sensibility and determine positive and negative predictive values. Finally, the present findings suggest that the combination test improves, and allows an increase in, the diagnostic accuracy of pulmonary TB in the Warao childhood population when used together with clinical and epidemiological criteria. In addition to efficient diagnosis, political commitment and public health education at different levels of the government as well as in the Warao population are probably the most important aspects of TB control. 


\section{ACKNOWLEDGEMENTS}

To Mark Gregson for critical review of the manuscript. To Yaneth Hernández for her technical assistance. To Dr Rodriguez, pneumologist, Regional Coordinator of the National Tuberculosis Program, and Dr Del Nogal, Coordinator of the Pediatric Post-Graduate Degree of the Children's Hospital "J.M. de los Rios" in Caracas for confirming the radiology evaluations and to Dr Mireya Mendoza for providing the Candida albicans antigen.

\section{REFERENCES}

Adams JF, Scholvinck EH, Gie RP, Potter PC, Beyers N, Beyers AD 1999. Decline in total serum IgE after treatment for tuberculosis. Lancet 353(9169): 2030-2033.

Alde SLM, Piñasco HM, Pelosi FR, Budani HF, Palma-Beltran OH, Gonzalez Montaner LJ 1989. Evaluation of an enzyme-linked immunosorbent assay (ELISA) using an IgG antibody to Mycobacterium tuberculosis antigen 5 in the diagnosis of active tuberculosis in children. Am Rev Respir Dis 139: 748-751.

Alifano M, Sofia M, Mormile M, Micco A, Mormile AF, Del Pezzo M, Carrat'u L 1996. IgA immune response against the mycobacterial antigen A60 in patients with active pulmonary tuberculosis. Respiration 63: 292-297.

Araujo Z, Fernández de Larrea C, López D, Fandiño C, Chirinos M, Convit J, Debora I, de Waard JH 2003. Hematologic values among Warao indians with tuberculosis from the Orinoco delta of Venezuela. Acta Cient Venez, 54: 247-253.

Arends T 1992 Estructura Genética de la Población Indígena de Venezuela, La Universidad de las Naciones Unidas, Caracas, 85 pp.

Arnadottir T, Rieder HI, Trébuq A, Waaler H 1996. Guidelines for conducting tuberculin skin test surveys in high prevalence countries. Tuber Lung Dis 77: 1-20.

Barrera I, Miceli I, Ritacco V 1989. Detection of circulating antibodies to purified protein derivative by enzyme linked immunosorbent assay: its potential for the rapid diagnosis of tuberculosis. Pediatr Infect Dis J 8: 763-767.

Beyer AD, van Rie A, Adams J, Fenhalls G, Gie R, Beyers N 1998. Signals that regulate the host response to Mycobacterium tuberculosis. Novartis Found Symp 217: 145-157.

Chiang IH, Suo J, Bai KJ, Lin TP, Luh KT, Yu CJ, Yang PC 1997. Serodiagnosis of tuberculosis. A study comparing three specific mycobacterial antigens. Am J Respir Crit Care Med 156: 906-1011.

Daniel TM, Debane SM 1987. The serodiagnosis for tuberculosis and other mycobacterial diseases by enzyme-linked immunosorbent assay. Am Rev Respir Dis 135: 1137-1151.

Eamranond P, Jaramillo E 2001. Tuberculosis in children: reassessing the need for improved diagnosis in global control strategies. Int J Tuberc Lung Dis 5: 594-603.

Fernández de Larrea C, Fandiño C, López D, del Nogal B, Rodríguez N, Convit J, Araujo Z, de Waard JH 2002. Childhood tuberculosis in the Warao population in Venezuela. Invest Clin 43: 35-48.

González N, de Cubeddu L, de Waard JH, Fandiño C, Fernández de Larrea C, López D, Maldonado A, Ocaña Y, Hernández E, Ortega R, Convit J, Pujol FH, Castés M, Araujo Z 2003. Study of the immune response in Warao children from an area with high prevalence of tuberculosis. Invest Clin 44: 303-318.

Gupta S, Bathia R, Datta KK 1997. Serological diagnosis of childhood tuberculosis by estimation of mycobacterial antigen 60-specific immunoglobulins in the serum. Tubercle Lung Dis 78: 21-27.

Honore S, Vincensini JP, Hocqueloux L, Noguera ME, Farge D,
Lagrange P, Hermann JL 2001. Diagnostic value of a nested polymerase chain reaction assay on peripheral blood mononuclear cells from patients with pulmonary and extra-pulmonary tuberculosis. Int J Tuberc Lung Dis 5: 754-762.

Houwert K, Borggreven P, Schaaf H, Nel E, Donadl P, Stolk J 1998. Prospective evaluation of World Health Organization criteria to assist diagnosis of tuberculosis in children. Eur Respir J 11: 1116-1120.

Imaz MS, Comini MA, Zerbini E, Sequeira MD, Spoletti MJ, Etchart AA, Pagano HJ, Bonifasich E, Díaz N, Claus JD, Singh M 2001. Evaluation of the diagnostic value of measuring IgG, IgM and IgA antibodies to the recombinant 16kilodalton antigen of tuberculosis in childhood tuberculosis. Int J Tuberc Lung Dis 5: 1036-1043.

Jackett PS, Bothamley GH, Batra HV, Mistry A, Young DB, Ivanyi J 1988. Specificity of antibodies to immunodominant mycobacterial antigens in pulmonary tuberculosis. J Clin Microbiol 26: 2313-2318.

Kudoh S, Kudoh T 1974. A simple technique for culturing tubercle bacilli. Bull WHO 51:71-82.

López Blanco M, Landaeta M 1991. Manual de Crecimiento y Desarrollo, Fundacredesa, Caracas.

Mabey D, Peeling RW, Ustianowski A, Perkins MD 2004. Diagnostics for the developing world. Nature Rev 2: 231-239.

McMurray DN, Echeverri A 1978. Cell-mediated immunity in anergic patients with pulmonary tuberculosis. Am Rev Respir Dis 118: 827-834.

Migliori G, Borghesi A, Rossanigo P, Adriko C, Neri M, Santini S, Bartolini A, Paradisi F, Acocella G 1992. Proposal of an improved score method for the diagnosis of pulmonary tuberculosis in childhood in developing countries. Tuber Lung Dis 73: 145-149.

MSAS-Ministerio de Sanidad y Asistencia Social 1996. Normas para el primer nivel de atención. 1996. Actualización. Programa Nacional Integrado de control de la tuberculosis. División de tuberculosis y enfermedades pulmonares, Caracas, Venezuela.

MSAS-Ministerio de Sanidad y Asistencia Social 1999. Seminario Técnico-Administrativo. Programa Integrado de Control de la Tuberculosis. Caracas, Venezuela.

MSDS-Ministerio de Salud y Desarrollo Social 2002. Evaluación del Programa Nacional de Control de la Tuberculosis Año 2002. Año evaluado 2001. Caracas, Venezuela.

OCEI-Oficina Central de Estadística e Informática 1992. Censo indígena de Venezuela 1992. Nomenclador de asentamientos. Tomo II. Caracas.

Pottumarthy S, Wells VC Morris AJ 2000. A comparison of seven tests for serological diagnosis of tuberculosis. J Clin Microbiol 38: 2227-2231.

Radin RC, Zeiss CR, Phair JP 1983. Antibodies to purified protein derivative in different immunoglobulin classes in the diagnosis of tuberculosis in man. Int Arch Allergy Immunol 70: 25-29.

Raja A, Ranganathan UD, Bethunaickan R, Dharmalingam V 2001. Serologic response to a secreted and a cytosolic antigen of tuberculosis in childhood tuberculosis. Pediatr Infec Dis 20: 1161-1164.

Raja A, Uma Devi KR, Ramalingam B, Brennan PJ 2002. Immunoglobulin G, A and $M$ responses in serum and circulating immune complex elicited by the 16-kilodalton antigen of tuberculosis. Clin Diagn Lab Immunol 9: 308-312.

Sant'Anna CC, Ferreira MAS, Fonseca LS 1999. Evaluation of a serological method (ELISA) for the diagnosis of pulmonary tuberculosis in children. Int J Tuberc Lung Dis 3: 744748.

Snider DE 1982. The tuberculin skin test. Am Rev Respir Dis 
125: 102-104.

Starke JR 1993. Childhood tuberculosis: a diagnostic dilemma. Chest 104: 329-330.

Swaminathan S, Umadevi P, Shantha S, Radhakrishnan A, Datta 0 1999. Sero diagnosis of tuberculosis in children using two ELISA kits. Indian J Pediatr 66: 837-884.

Uma Devi KR, Ramalingam B, Brennan PJ, Narayanan PR, Raja A 2001. Specific and early detection of IgG, IgA and IgM antibodies to tuberculosis $38 \mathrm{kDa}$ antigen in pulmonary tuberculosis. Tuberculosis 81: 249-253.

WHO-World Health Organization 2003. The Americas: Summary of TB control policies. Report.

Wright PW, Crutcher JE, Holiday DB 1995. Selection of skin test antigens to evaluate PPD anergy. J Fam Pract 41: 5964.

Yong AJ, Grange JM, Tee RD 1989. Total and anti-mycobacterial IgE levels in serum from patients with tuberculosis and leprosy. Tubercle 70: 273-279.

Young D, Kent L, Rees A, Lamb J, Ivanyi, J 1986. Immunological activity of a 38-kilodalton purified from Mycobacterium tuberculosis. Infect Immun 54: 177-183.

Zheng YJ, Wang RH, Lin YZ, Daniel TM 1994. Clinical evaluation of the diagnostic value of measuring IgG antibody to three mycobacterial antigen preparations in the capillary blood of children with tuberculosis and control subjects. Tubercle Lung Dis 75: 366-370. 